\title{
Neutrophil contribution to spinal cord injury and repair
}

\author{
Virginie Neirinckx ${ }^{1}$, Cécile Coste ${ }^{1}$, Rachelle Franzen ${ }^{1}$, André Gothot ${ }^{2,3}$, Bernard Rogister ${ }^{1,4,5}$ and Sabine Wislet ${ }^{1 *}$
}

\begin{abstract}
Spinal cord injuries remain a critical issue in experimental and clinical research nowadays, and it is now well accepted that the immune response and subsequent inflammatory reactions are of significant importance in regulating the damage/repair balance after injury. The role of macrophages in such nervous system lesions now becomes clearer and their contribution in the wound healing process has been largely described in the last few years. Conversely, the contribution of neutrophils has traditionally been considered as detrimental and unfavorable to proper tissue regeneration, even if there are very few studies available on their precise impact in spinal cord lesions. Indeed, recent data show that neutrophils are required for promoting functional recovery after spinal cord trauma. In this review, we gathered recent evidence concerning the role of neutrophils in spinal cord injuries but also in some other neurological diseases, highlighting the need for further understanding the different mechanisms involved in spinal cord injury and repair.
\end{abstract}

Keywords: Inflammation, Spinal cord injury, Neutrophils, G-CSF

\section{Background}

According to the last update reported by Lee and colleagues [1], the global incidence of traumatic spinal cord injuries (SCI) was estimated in 2007 at 23 cases per million worldwide. Reported SCI cases mainly concern young adult men, for the most part victims from motor vehicle accidents and falls [2]. Cervical and lumbar spines are the most commonly affected regions, inducing respectively tetraplegia and paraplegia. Patients suffer from motor impairments, spasticity, neuropathic pain, reflexive, sphincter, sexual and sensitive troubles, accompanied by highly disabling financial and social issues. Although experimental and clinical research have provided significant improvements in medical management and clinical recuperation after SCI in the last decade, no treatment allows complete functional recovery of patients, whatever the considered therapeutic strategy.

The development of such efficient treatments should first be based on the complete understanding of SCI physiopathological events. Those events are gathered in three major phases (acute, sub-acute and chronic), as previously

\footnotetext{
* Correspondence: s.wislet@ulg.ac.be

${ }^{1}$ GIGA Research Center, Neurosciences Unit, Nervous system diseases and treatment, University of Liège, Avenue de l'Hôpital, 1, 4000 Liège, Belgium Full list of author information is available at the end of the article
}

reviewed [3,4]. Briefly, 1) the acute phase events after traumatic SCI and spinal shock encompass axonal disruption and neuronal death, blood supply default and ischemia, edema, invasion of granulocytes, disruption in ionic balance and neurotransmitter release; 2 ) the sub-acute (intermediate) stage starts around 7 days after the lesion and is characterized by further oxidative stress taking place by lipid peroxidation and free-radical production, as well as by the recruitment of macrophages and lymphocytes, which secrete cytokines and promote the development of an inflammatory environment; 3 ) the chronic phase arises after a few weeks to months, encompassing continuous alteration of ionic balance, apoptosis of oligodendrocytes and consequent demyelination, cavities and astroglial scar formation, persisting for years. Overall, those unfavorable events hamper axonal regrowth and functional recovery.

Accordingly, administration of high doses of methylprednisolone in the first hours after SCI was shown to reduce lesion extent and to limit motor decline in patients [5]. Up to now, corticosteroid administration remains the most efficient attempt to cure SCI patients by counteracting the inflammatory reaction. However, no complete regeneration can be achieved despite great advances, and thus, the fine-tuning of the inflammatory reaction should be more precisely considered. 
As already mentioned, host inflammatory response after SCI largely contributes to the elaboration of unfavorable tissue environment. Paradoxically, several studies pointed out that the inflammatory reaction could be mandatory in order to initiate efficient tissue repair [6]. Basically, early inflammatory events involve sequential recruitment of three main types of peripheral immune cells: 1) neutrophils are the first inflammatory cells to arrive at the site of injury, with a peak at 24 hours postinjury. Those cells phagocyte and clear debris, secrete proteases, elastase, myeloperoxidase and release reactive oxygen species (ROS); 2) circulating monocytes/macrophages are subsequently recruited (peak at 7 days postinjury), release cytokines such as TNF- $\alpha$, IL- $1 \beta$, nitric oxide, prostaglandins and leukotrienes, and also exert important phagocytic abilities; 3) lymphocytes progressively invade the lesion site, concomitantly to macrophages and secrete cytokines in the lesion epicenter. However, the number of recruited lymphocytes remains low compared to other cell types [7-9] (Figure 1).

Noteworthy, microglial cells of the spinal cord tissue contribute to the inflammatory reaction as well (reviewed in [10]), even if the distinction between those resident macrophages and peripheral blood-derived macrophages is still difficult to establish and their respective roles in SCI remain under investigation. Indeed, it appears that microgliocytes and peripheral monocytes differentially contribute to SCI recovery [11], and present distinct timeframes of action and phagocytic activities [12].

Macrophages have been the most studied immune cells in the context of spinal cord inflammation for many years and are now considered as crucial for tissue repair and functional recovery [13,14]. Exciting experimental results even led to clinical application of autologous macrophage-based therapies for SCI, even if further investigations are needed to characterize the significant effect of such interventions $[15,16]$.
Nonetheless, scientists kept on delineating the mechanisms by which monocytes/macrophages were acting in the spinal cord after traumatic injuries. Two subtypes of macrophages were recently identified and classified as classically activated M1 macrophages, and alternatively activated M2 macrophages. Basically, M1 macrophages secrete IL- $1 \beta$, TNF $\alpha$ and ROS, promoting tissue destruction and killing of parasites, whereas M2 macrophages secrete IL-10, IL-1RA or chemokines and induce tissue remodeling $[17,18]$. Both of those subtypes exert contrasting immunomodulatory actions in pathological conditions and especially in SCI $[19,20]$. Therefore, it appears that M2 macrophages are of great interest with regard to SCI therapy, as recently reviewed [21].

Altogether, existing evidence reveals that scientists reach a consensus about the required role of immunity and inflammation in nervous system disorders, and in spinal cord injuries in particular, while the understanding of molecular and cellular mechanisms by which each type of immune cells is acting is still under progress. However, as inflammation essentially implies sequential recruitment and activation of neutrophils and macrophages, it is surprising to note that the roles of the former are quite less known compared to the roles of the latter. Therefore, in this review, we will gather information about neutrophils and detail what is known about the different actions they could exert in the damaged nervous tissue, in an effort to reconsider the controversial role of those intriguing cells in spinal cord traumatic lesions.

\section{Neutrophils - origin, identification and general role in inflammatory response}

Granulocytes are a subset of white blood cells characterized by their polylobulated nucleus and by their cytoplasmic granules, which are differentially identified by cytological stainings and allow distinction between

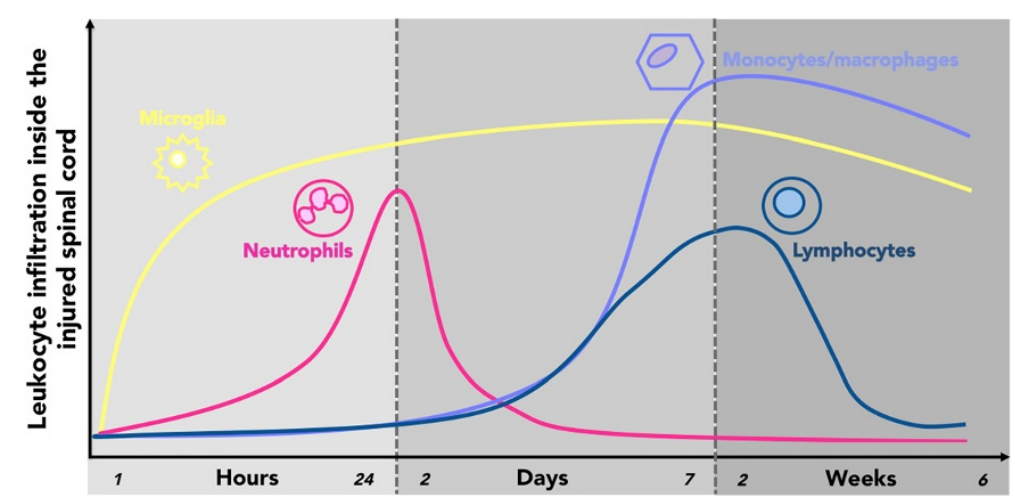

Figure 1 Global temporal sequence of leukocyte recruitment of the spinal cord after injury in rodents. (Adapted from [6]). 
basophil, eosinophil and neutrophil granulocytes. Granulocytes arise from granulo-monocytic progenitors in the bone marrow (Figure 2). Primary cell fate determinants of the granulocytic and monocytic lineages are transcription factors PU.1 and C/EBP $\alpha$. High levels of PU.1 promote a macrophage differentiation program through the secondary determinants Egr1,2/Nab-2, while repressing neutrophil-specific genes. Conversely, elevated levels of C/EBP $\alpha$ and secondary GFi-1 induce granulocytic differentiation, while antagonizing monocyte development (as reviewed by $[22,23]$ ). Primary granules appear at the promyelocyte stage and contain microbicidal proteins and acid hydrolases such as myeloperoxidase and lysozyme. Promyelocytes then develop into myelocytes, which display secondary or specific granules of neutrophilic, eosinophilic or basophilic cytochemical characteristics, and contain other hydrolases and chemotactic factors. Tertiary granules include secretory vesicles containing plasma proteins, and gelatinase granules. While primary granules are discharged exclusively into phagosomes, secondary and tertiary granules are released both outside the cell and in the extracellular medium.

A network of hematopoietic growth factors and cytokines (for example, granulocyte colony-stimulating factor (GCSF)) regulates the production of granulocytic cells. G-CSF is a major regulator of neutrophilic granulocyte production and modulates the proliferation, survival, maturation and functional activation of these cells [24]. By activating the release of proteases from granulocytes, G-CSF induces a massive egress of immature cells from the bone marrow, including hematopoietic and non-hematopoietic stem cells, as well as granulocytic progenitors and precursors [25].

During bacterial infection or traumatic lesion, neutrophils are recruited from the bloodstream and migrate across endothelial barriers to reach the inflammatory site, being highly sensitive to chemoattractant signals such as

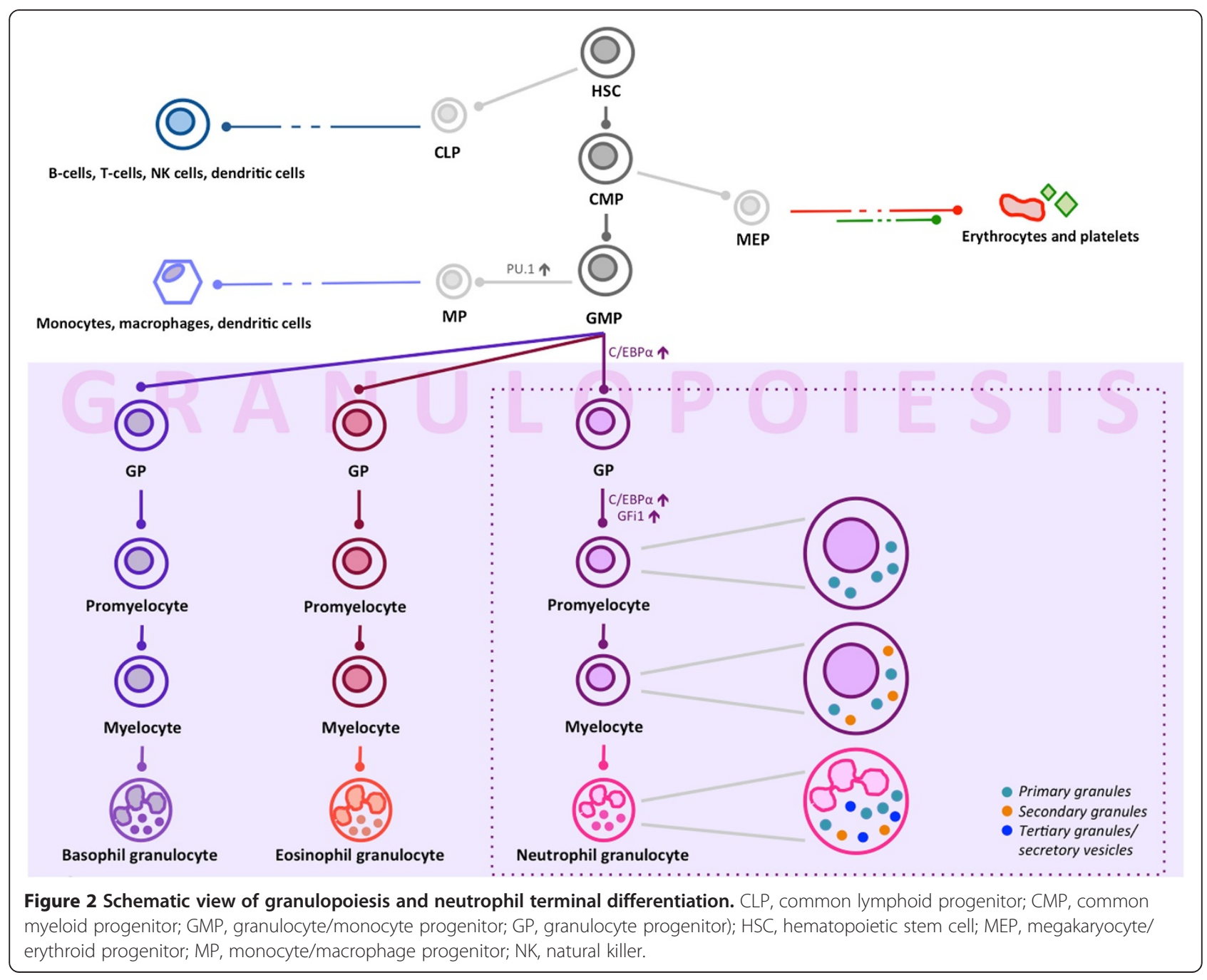


IL-8, interferon-gamma and C5a. Other signals such as the CXCL12-CXCR4 or CXCL1/2-CXCR2 signalization pathways also regulate neutrophil mobilization and activation in inflammatory conditions, including in nervous system disorders [26-30]. Once recruited at their site of action, neutrophils roll and adhere to endothelial barriers before crossing over; they reach the lesion and secrete cytokines, release their cytoplasmic secondary and tertiary granule content, phagocyte cell debris, and form neutrophil extracellular traps [31], altogether clearing the lesioned tissue and/or microbes in a complex network of pathways. Cellular and molecular details concerning recruitment and activity of neutrophils in health and disease are reviewed in depth in [32,33].

Granulocytes are specifically identified by the expression of surface antigens CD66b and CD11b/c, which are responsible for adhesion and cell-cell interaction; and CD13, CD16 or CD88 (among others) mediating different aspects of the immune response. Murine granulocytes also express Ly6g and Ly6C members of the Ly6 family, potentially involved in neutrophil recruitment and migration [34]. These markers are often used for leukocyte subset identification and targeted in antibody-mediated depletion strategies [34,35], providing numerous insights into neutrophil biological function in a wide panel of domains.

\section{Neutrophil implication in spinal cord injuries}

Neutrophils are usually considered as the "bad guys", bluntly accumulating in the inflammatory core of a tissue lesion, secreting proteases, oxidative and tissue-degrading enzymes, thus elaborating a harmful tissue environment. Likewise, most of the studies describe them as detrimental actors. More specifically, neutrophils have been described to promote neurotoxicity on dorsal root ganglia neurons via the activity of matrix metalloproteinase 9, generation of ROS and secretion of TNF- $\alpha$ [36]. Cell-cell contact between neutrophils and neurons also seem to generate cytotoxicity [37].

Very few papers have focused on the role of neutrophils in SCI models, but their detrimental action was mainly highlighted as an effect/consequence of other treatments and conditions. Indeed, in most conditions, a lower neutrophil accumulation in the lesion was associated with reduced pro-inflammatory cytokines, reduced apoptosis and oxidative stress and significant motor recovery (see Additional file 1: Table S1). Besides underlining the deleterious effect of neutrophils, these studies also provided clues about the different ways in which these cells are recruited in the injured tissue. For instance, it was shown that neutrophil infiltration in the damaged spinal cord was reduced after blocking the leukotriene B4/ BLT1 receptor signaling [38], after inhibiting phosphodiesterase 4 [39] or in absence of myeloperoxidase [40].
The role of the NF- $\mathrm{BB}$ signaling pathway was suggested, both in neutrophil invasion and in neutrophil activity in the lesion. Indeed, the blockade of inhibitor of NF- $\kappa B$ kinase subunit $\beta$ (IKK $\beta)$ neutralized the secretion of CXCL1 and the subsequent neutrophil infiltration, but also the expression of pro-inflammatory genes, simultaneously improving tissue preservation and motor function [41].

Together with the chemokines CCL2 and CXCL2, CXCL1 was proposed as a neutrophil chemoattractant, which would be secreted by spinal cord astrocytes under IL-1 receptor (IL-1R)/MyD88 signalization [42], and which even seemed to mediate neuropathic pain [43]. Consistently, the concentration of CXCL1 in the serum of SCI patients is increased in the first week following injury, compared to healthy patients [44].

All these results essentially classify neutrophils as unfavorable actors in the inflammatory response, still it appears that their roles in injury/repair processes need to be more specifically addressed. Indeed, as clearly depicted in Additional file 1: Table S1, the specific activity of neutrophils in the spinal cord is largely unknown. There is now increasing evidence that neutrophils also exert at least indirect beneficial effects, probably by initiating inflammation-associated tissue repair, thus prompting us to re-evaluate and nuance the beneficial/harmful role of neutrophils in the injured spinal cord.

Recent specific antibody-based methods of Ly6G/Gr-1 $1^{+}$ neutrophil depletion $[34,45]$ revealed that the presence of neutrophils unexpectedly reduced the levels of ROS in a spinal cord lesion [46]. Surprisingly, Stirling and colleagues showed that the depletion of Ly6G/Gr- $1^{+}$neutrophils impaired the functional outcome in SCI mice, by preventing early vascular recruitment, rolling and adhesion to endothelia, spinal cord tissue infiltration, and exacerbating CXCL1, CCL2, G-CSF and CCL9 production inside the spinal cord as a compensatory attempt [47]. This study definitively demonstrated, for the first time, that neutrophils were required for appropriate inflammatory reaction and subsequent tissue repair after SCI. A few months later it was shown that secreted leukocyte protease inhibitor (SLPI) was required for SCI recovery. SLPI is secreted by neutrophils and astrocytes in the spinal cord tissue [48], which highlights a hypothetical mechanism underlying positive neutrophil action. On the other hand, neutrophils accumulate in the injured spinal cord of mice lacking tenascin- $\mathrm{C}$, while axonal fibers penetrate easier through the spinal cord tissue [49], suggesting that neutrophils could contribute to the elaboration of a suitable environment for axonal regeneration.

\section{Neutrophils in other nervous system disorders}

Neutrophils [50] and oxidative stress [51] are frequently associated with the pathogenesis of Alzheimer's disease 
(AD). However, this aspect is quite controversial as several studies suggested that the number and function of circulating neutrophils were reduced in $\mathrm{AD}$ patients [52-54] as a consequence of the disease. New insights in the physiopathological processes of AD showed that neutrophils migrate towards amyloid plaques, maybe suggesting a potential interaction worthy of thorough characterization [55] in order to specify the role of neutrophils in AD pathogenesis.

It is also well accepted that neutrophils are a key player of the regulatory sequence of experimental autoimmune encephalomyelitis (EAE), essentially recruited and activated by inflammatory chemokines such as CXCL1, CXCL2 or CCL2 [56-58]. They are also involved in blood brain barrier disruption during the onset of experimental autoimmune encephalomyelitis in mice, probably because of an increased IL-1R-dependent transmigration ability [59].

Despite the demonstration of the numerous detrimental consequences associated with neutrophils, there is a noticeable gap of knowledge about how neutrophils are properly working in brain and spinal cord injuries. Noteworthy, recently published data now tend to reverse the trend and suggest that the role of neutrophils could be more balanced than it seems. Whereas the contribution of neutrophils to tissue repair and recovery from experimental stroke was highlighted several years ago (as reviewed in [60]), recently published results addressed the specific impact of neutrophils in inflammation-induced regeneration of the optic nerve and in peripheral nerve regeneration (Additional file 1: Table S1). Indeed, Yin and colleagues demonstrated that neutrophils are recruited during the first three days after zymosan-induced optic nerve inflammation, and secrete high levels of oncomodulin. Interestingly, macrophages that reach the lesion later on also secrete oncomodulin. Oncomodulin is a $12-\mathrm{kDa}$ calcium-binding protein, which is secreted by neutrophils and macrophages, and was previously demonstrated to support neural regeneration in retinal ganglion cells in culture [61] and in the optic nerve [62]. However, macrophages alone are not sufficient to induce regeneration in the optic nerve when neutrophil recruitment is specifically prevented [63], suggesting an essential role for neutrophils and their specific oncomodulin secretion inside the optic nerve.

Neutrophils have been designated as responsible for hypersensitivity/neuropathic pain occurring after peripheral nerve injury $[64,65]$. Once again, however, several observations suggest a role for neutrophils in peripheral nerve regeneration. It has been shown that axonal regrowth after peripheral nerve injury was abolished in the absence of myeloid cells, which are specifically required to clear myelin debris and secrete neurotrophic factors such as neurotrophin-3,4,5 and brain-derived neurotrophic factor. Interestingly, it seemed that spinal cord axons needed myeloid cell support as well to properly regenerate in a peripheral nerve graft [66].

\section{Granulocyte colony-stimulating factor: its implication in experimental spinal cord injury, and clinical data}

G-CSF is an important regulating factor of neutrophil development, recruitment and activity in physiological and pathological conditions. As stated below, G-CSF is largely described in SCI experimental models and in clinical trials because of its plenty of properties, both on the hematological and neurological points of view. Importantly, a hypothetic G-CSF-dependent role of neutrophils in SCI would be worth considering. Details about G-CSF activity in SCI are therefore of significant interest in order to further define the precise aspects of the inflammatory response after lesion.

Fundamentally, G-CSF is a $19,6-\mathrm{kDa}$ glycoprotein [67] that binds on a specific G-CSF receptor at the surface of hematopoietic stem cells from the bone marrow, promoting their proliferation and differentiation into granulocytes, which are further released in the peripheral bloodstream. G-CSF also modulates mature neutrophil proliferation, activation and recruitment, therefore playing a pivotal role in the regulation of inflammatory responses. G-CSF induces mobilization of bone marrow stem cells into the peripheral blood through an indirect mechanism involving degradation of adhesion molecules by proteases released from activated neutrophils [68]. On the other hand, it has been shown that G-CSF receptor was also expressed by neurons of the central nervous system, and that G-CSF has neurotrophic actions via anti-apoptotic, anti-excitotoxic and pro-neurogenic abilities [69] as particularly addressed in models of cerebral ischemia [70,71], amyotrophic lateral sclerosis [72,73] or in the study of memory and cognitive functions [74]. Therefore, besides being extensively used in the clinic to counteract chemotherapy-associated neutropenia [75] and collect hematopoietic stem cells by apheresis [76], G-CSF was also proposed as a therapeutic option for the treatment of SCI. Indeed, Japanese researchers recently applied G-CSF as a clinical treatment for patients suffering from SCI. Modest but non-negligible motor and sensory improvements were observed, whereas no adverse effects were reported [77-79], suggesting a potential beneficial effect of G-CSF in the therapy of SCI.

Different studies have already evidenced the beneficial effects of G-CSF in experimental models of SCI [80,81], which seem to be mainly associated with the prevention of excitotoxicity and apoptotic neuronal death, through several possible mechanisms [82]. G-CSF upregulates chaperone proteins, such as nucleophosmin-1 in motoneurons after spinal cord hemisection [83], reduces myeloperoxidase activity and lipid peroxidation [84] and 
increases glial cell line-derived neurotrophic factor and vascular endothelial growth factor A expression in glial cells after spinal cord ischemia [85]. It also appears that G-CSF-associated neuroprotection, through its mobilization capacity, is equivalent to bone marrow mononuclear stem cell-induced neuroprotection [86]. Besides acting on neural cells, G-CSF also modulates inflammatory reaction and immune cell recruitment and activation in the injured spinal cord. Recent data showed that GCSF induces alternative activation of microglial macrophages, thus promoting tissue repair [87]. Combined with stem cell factor administration, G-CSF increases the number of activated microglial cells and oligodendrocytes [88], whilst saving oligodendrocytes from SCI-induced cell death by reducing IL- $1 \beta$ and TNF- $\alpha$ and up-regulating the anti-apoptotic protein $\mathrm{Bcl}-\mathrm{xL}$ [89]. Additional data are now required to elucidate a putative intermediate role of neutrophils in G-CSFmediated effects on SCI.

\section{Conclusions}

Although the prevalent view emerging from the current literature depicts neutrophils in SCI as cells with harmful actions and effects, recent data strongly suggest that their inflammatory function could oppositely provide valuable outcome for tissue repair. Indeed, it appears that neutrophils have always been classically considered as damaging despite the lack of knowledge on their precise mechanisms of actions after SCI. While neutrophils have their own activity by secreting enzymes or other molecules, their fine interactions with other immune cells (for example, macrophages) may accurately guide the inflammatory process as well. Neutrophils are important inducers of the inflammatory sequence, as observed in models of rheumatoid arthritis [90], antibody-mediated inflammation [91], or acute respiratory distress syndrome [92]. Indeed, neutrophils set the stage for macrophages which phagocyte debris and clean the lesioned tissue, in different inflammatory conditions such as bacterial infection [93,94] or physical exercise [95], among others. Besides, neutrophils also interact with $\mathrm{T}$ lymphocytes and natural killer cells, as recently reviewed [96]. It has also been demonstrated that neutrophils can promote wound repair by releasing angiogenic factors such as IL-8 or vascular endothelial growth factor, and then inducing neovascularization, which is crucial for inflammation-mediated tissue remodeling $[97,98]$.

In addition, neutrophil-induced positive effects could also be linked to intrinsic properties of sub-populations. As described in several types of cancers, tumor-associated neutrophils are classified according to their pro- or antitumoral global actions as N1 (pro-tumor) and N2 (antitumor) [99]. As no phenotypic analysis of neutrophils has ever been carried out in traumatic lesions of the nervous system, one can imagine that the same duality could be translated, just as it is the case for the M1/M2 macrophage dyad (see above).

Overall, the lack of knowledge about the proper role of neutrophils in SCI and repair now becomes blindingly obvious. Neutrophils have usually been considered as deleterious actors to target for reducing lesion extent; however, it is now clear that their role must be thoroughly questioned. Further information about their cellular and molecular mechanisms of action should provide new insights in the field of SCI, and also in neurological diseases in general.

\section{Additional file}

Additional file 1: Table S1. Recruitment and activity of neutrophils in spinal cord injuries and other nervous system lesions.

\section{Abbreviations}

AD: Alzheimer's disease; G-CSF: granulocyte colony-stimulating factor; IKKB: inhibitor of NF-KB kinase subunit $\beta$; IL: interleukin; IL-1R: interleukin-1 receptor; NF: nuclear factor; $\mathrm{ROS}$ : reactive oxygen species; $\mathrm{SCl}$ : spinal cord injuries; SLPI: secreted leukocyte protease inhibitor; TNF: tumor necrosis factor.

\section{Competing interests}

The authors declare that they have no competing interests.

\section{Authors' contributions}

VN conceived the design, provided analysis and interpretation of data, and drafted and revised the manuscript. CC revised and critically appraised the manuscript for intellectual content. RF, AG, BR and SW provided analysis and interpretation of data, revised and critically appraised the manuscript for intellectual content. All authors read and approved the final version of the manuscript.

\section{Acknowledgements}

This work was supported by a grant from the Fonds National de la Recherche Scientifique (FNRS) and Télévie of Belgium, by the Belgian League against Multiple Sclerosis associated with the Léon Frédéricq Foundation and by the Fonds Spéciaux à la Recherche of the University of Liège.

\section{Author details}

${ }^{1}$ GIGA Research Center, Neurosciences Unit, Nervous system diseases and treatment, University of Liège, Avenue de l'Hôpital, 1, 4000 Liège, Belgium. ${ }^{2}$ GIGA Research Center, Cardiovascular sciences Unit, University of Liège, Avenue de l'Hôpital, 1, 4000 Liège, Belgium. ${ }^{3}$ Hematobiology Department, University Hospital Liège, Avenue de l'Hôpital, 1, 4000 Liège, Belgium. ${ }^{4} \mathrm{GIGA}$ Research Center, Stem Cells and Regenerative Medicine Unit, University of Liège, Avenue de l'Hôpital, 1, 4000 Liège, Belgium. ${ }^{5}$ Neurology Department, University Hospital Liège, Avenue de l'Hôpital, 1, 4000 Liège, Belgium.

Received: 11 June 2014 Accepted: 12 August 2014

Published: 28 August 2014

\section{References}

1. Lee BB, Cripps RA, Fitzharris M, Wing PC: The global map for traumatic spinal cord injury epidemiology: update 2011, global incidence rate. Spinal Cord 2013, 52:110-116.

2. Spinal cord injury facts and figures at a glance. J Spinal Cord Med 2012, 35:480-481.

3. Oyinbo CA: Secondary injury mechanisms in traumatic spinal cord injury: a nugget of this multiply cascade. Acta Neurobiol Exp (Wars) 2011, 71:281-299.

4. Ronaghi M, Erceg S, Moreno-Manzano V, Stojkovic M: Challenges of stem cell therapy for spinal cord injury: human embryonic stem cells, 
endogenous neural stem cells, or induced pluripotent stem cells? Stem Cells 2010, 28:93-99.

5. Young W, Bracken MB: The Second National Acute Spinal Cord Injury Study. J Neurotrauma 1992, 9(Suppl 1):S397-S405.

6. Donnelly DJ, Popovich PG: Inflammation and its role in neuroprotection, axonal regeneration and functional recovery after spinal cord injury. Exp Neurol 2008, 209:378-388.

7. Beck KD, Nguyen HX, Galvan MD, Salazar DL, Woodruff TM, Anderson AJ: Quantitative analysis of cellular inflammation after traumatic spinal cord injury: evidence for a multiphasic inflammatory response in the acute to chronic environment. Brain 2010, 133:433-447.

8. Fleming JC, Norenberg MD, Ramsay DA, Dekaban GA, Marcillo AE, Saenz $A D$, Pasquale-Styles M, Dietrich WD, Weaver LC: The cellular inflammatory response in human spinal cords after injury. Brain 2006, 129:3249-3269.

9. Stirling DP, Yong WW: Dynamics of the inflammatory response after murine spinal cord injury revealed by flow cytometry. J Neurosci Res 2008, 86:1944-1958.

10. David S, Kroner A: Repertoire of microglial and macrophage responses after spinal cord injury. Nat Rev Neurosci 2011, 12:388-399.

11. Shechter R, London A, Varol C, Raposo C, Cusimano M, Yovel G, Rolls A, Mack M, Pluchino S, Martino G, Jung S, Schwartz M: Infiltrating bloodderived macrophages are vital cells playing an anti-inflammatory role in recovery from spinal cord injury in mice. PLoS Med 2009, 6:e1000113.

12. Greenhalgh $A D$, David $S$ : Differences in the phagocytic response of microglia and peripheral macrophages after spinal cord injury and its effects on cell death. J Neurosci 2014, 34:6316-6322.

13. Rapalino O, Lazarov-Spiegler O, Agranov E, Velan GJ, Yoles E, Fraidakis M, Solomon A, Gepstein R, Katz A, Belkin M, Hadani M, Schwartz M: Implantation of stimulated homologous macrophages results in partial recovery of paraplegic rats. Nat Med 1998, 4:814-821.

14. Schwartz M, Yoles E: Immune-based therapy for spinal cord repair: autologous macrophages and beyond. J Neurotrauma 2006, 23:360-370.

15. Knoller N, Auerbach G, Fulga V, Zelig G, Attias J, Bakimer R, Marder JB, Yoles E, Belkin M, Schwartz M, Hadani M: Clinical experience using incubated autologous macrophages as a treatment for complete spinal cord injury: phase I study results. J Neurosurg Spine 2005, 3:173-181.

16. Lammertse DP, Jones LA, Charlifue SB, Kirshblum SC, Apple DF, Ragnarsson $K T$, Falci SP, Heary RF, Choudhri TF, Jenkins AL, Betz RR, Poonian D, Cuthbert JP, Jha A, Snyder DA, Knoller N: Autologous incubated macrophage therapy in acute, complete spinal cord injury: results of the phase 2 randomized controlled multicenter trial. Spinal Cord 2012, 50:661-671.

17. Mantovani A, Sica A, Locati M: New vistas on macrophage differentiation and activation. Eur J Immunol 2007, 37:14-16

18. Gordon S, Taylor PR: Monocyte and macrophage heterogeneity. Nat Rev Immunol 2005, 5:953-964

19. Kigerl KA, Gensel JC, Ankeny DP, Alexander JK, Donnelly DJ, Popovich PG: Identification of two distinct macrophage subsets with divergent effects causing either neurotoxicity or regeneration in the injured mouse spinal cord. J Neurosci 2009, 29:13435-13444.

20. Shechter R, Miller O, Yovel G, Rosenzweig N, London A, Ruckh J, Kim KW Klein E, Kalchenko V, Bendel P, Lira SA, Jung S, Schwartz M: Recruitment of beneficial M2 macrophages to injured spinal cord is orchestrated by remote brain choroid plexus. Immunity 2013, 38:555-569.

21. Shin T, Ahn M, Moon C, Kim S, Sim KB: Alternatively activated macrophages in spinal cord injury and remission: another mechanism for repair? Mol Neurobiol 2013, 47:1011-1019.

22. Fiedler $\mathrm{K}$, Brunner $\mathrm{C}$ : The role of transcription factors in the guidance of granulopoiesis. Am J Blood Res 2012, 2:57-65.

23. Ward AC, Loeb DM, Soede-Bobok AA, Touw IP, Friedman AD: Regulation of granulopoiesis by transcription factors and cytokine signals. Leukemia 2000, 14:973-990.

24. Lieschke GJ, Grail D, Hodgson G, Metcalf D, Stanley E, Cheers C, Fowler KJ, Basu S, Zhan YF, Dunn AR: Mice lacking granulocyte colony-stimulating factor have chronic neutropenia, granulocyte and macrophage progenitor cell deficiency, and impaired neutrophil mobilization. Blood 1994, 84:1737-1746.

25. Delgaudine $M$, Lambermont $B$, Lancellotti $P$, Roelants $V$, Walrand $S$ Vanoverschelde JL, Pierard L, Gothot A, Beguin Y: Effects of granulocyte-colonystimulating factor on progenitor cell mobilization and heart perfusion and function in normal mice. Cytotherapy 2011, 13:237-247.
26. Mei J, Liu Y, Dai N, Hoffmann C, Hudock KM, Zhang P, Guttentag SH, Kolls JK, Oliver PM, Bushman FD, Worthen GS: Cxcr2 and Cxcl5 regulate the IL-17/GCSF axis and neutrophil homeostasis in mice. J Clin Invest 2012, 122:974-986.

27. Johnson EA, Dao TL, Guignet MA, Geddes CE, Koemeter-Cox Al, Kan RK: Increased expression of the chemokines CXCL1 and MIP-1alpha by resident brain cells precedes neutrophil infiltration in the brain following prolonged soman-induced status epilepticus in rats. J Neuroinflammation 2011, 8:41.

28. Ritzman AM, Hughes-Hanks JM, Blaho VA, Wax LE, Mitchell WJ, Brown CR: The chemokine receptor CXCR2 ligand KC (CXCL1) mediates neutrophil recruitment and is critical for development of experimental Lyme arthritis and carditis. Infect Immun 2010, 78:4593-4600.

29. Eash KJ, Greenbaum AM, Gopalan PK, Link DC: CXCR2 and CXCR4 antagonistically regulate neutrophil trafficking from murine bone marrow. J Clin Invest 2010, 120:2423-2431.

30. Wengner AM, Pitchford SC, Furze RC, Rankin SM: The coordinated action of G-CSF and ELR + CXC chemokines in neutrophil mobilization during acute inflammation. Blood 2008, 111:42-49.

31. Brinkmann V, Reichard U, Goosmann C, Fauler B, Uhlemann Y, Weiss DS, Weinrauch $Y$, Zychlinsky A: Neutrophil extracellular traps kill bacteria. Science 2004, 303:1532-1535.

32. Kolaczkowska E, Kubes P: Neutrophil recruitment and function in health and inflammation. Nat Rev Immunol 2013, 13:159-175.

33. Wright HL, Moots RJ, Bucknall RC, Edwards SW: Neutrophil function in inflammation and inflammatory diseases. Rheumatology (Oxford) 2010, 49:1618-1631

34. Daley JM, Thomay AA, Connolly MD, Reichner JS, Albina JE: Use of Ly6Gspecific monoclonal antibody to deplete neutrophils in mice. J Leukoc Biol 2008, 83:64-70.

35. Tepper RI, Coffman RL, Leder P: An eosinophil-dependent mechanism for the antitumor effect of interleukin-4. Science 1992, 257:548-551.

36. Nguyen HX, O'Barr TJ, Anderson AJ: Polymorphonuclear leukocytes promote neurotoxicity through release of matrix metalloproteinases, reactive oxygen species, and TNF-alpha. J Neurochem 2007, 102:900-912.

37. Dinkel K, Dhabhar FS, Sapolsky RM: Neurotoxic effects of polymorphonuclear granulocytes on hippocampal primary cultures. Proc Natl Acad Sci U S A 2004, 101:331-336.

38. Saiwai $H$, Ohkawa $Y$, Yamada $H$, Kumamaru $H$, Harada A, Okano $H$, Yokomizo T, Iwamoto Y, Okada S: The LTB4-BLT1 axis mediates neutrophil infiltration and secondary injury in experimental spinal cord injury. Am J Pathol 2010, 176:2352-2366

39. Bao F, Fleming JC, Golshani R, Pearse DD, Kasabov L, Brown A, Weaver LC: A selective phosphodiesterase- 4 inhibitor reduces leukocyte infiltration, oxidative processes, and tissue damage after spinal cord injury. J Neurotrauma 2011, 28:1035-1049.

40. Kubota K, Saiwai H, Kumamaru H, Maeda T, Ohkawa Y, Aratani Y, Nagano T, Iwamoto Y, Okada S: Myeloperoxidase exacerbates secondary injury by generating highly reactive oxygen species and mediating neutrophil recruitment in experimental spinal cord injury. Spine (Phila Pa 1976) 2012, 37:1363-1369.

41. Kang J, Jiang MH, Min HJ, Jo EK, Lee S, Karin M, Yune TY, Lee SJ: IKK-betamediated myeloid cell activation exacerbates inflammation and inhibits recovery after spinal cord injury. Eur J Immunol 2011, 41:1266-1277.

42. Pineau I, Sun L, Bastien D, Lacroix S: Astrocytes initiate inflammation in the injured mouse spinal cord by promoting the entry of neutrophils and inflammatory monocytes in an IL-1 receptor/MyD88-dependent fashion. Brain Behav Immun 2010, 24:540-553.

43. Zhang ZJ, Cao DL, Zhang X, Ji RR, Gao YJ: Chemokine contribution to neuropathic pain: respective induction of CXCL1 and CXCR2 in spinal cord astrocytes and neurons. Pain 2013, 154:2185-2197.

44. Hassanshahi G, Amin M, Shunmugavel A, Vazirinejad R, Vakilian A, Sanji M, Shamsizadeh A, RafatPanah H, Poor NM, Moosavi SR, Taheri S: Temporal expression profile of CXC chemokines in serum of patients with spinal cord injury. Neurochem Int 2013, 63:363-367.

45. Conlan JW, North RJ: Neutrophils are essential for early anti-Listeria defense in the liver, but not in the spleen or peritoneal cavity, as revealed by a granulocyte-depleting monoclonal antibody. J Exp Med 1994, 179:259-268.

46. De Castro JR, Hughes MG, Xu G-Y, Clifton C, Calingasan NY, Gelman BB, McAdoo DJ: Evidence that infiltrating neutrophils do not release reactive 
oxygen species in the site of spinal cord injury. Exp Neurol 2004, 190:414-424.

47. Stirling DP, Liu S, Kubes P, Yong W: Depletion of Ly6G/Gr-1 leukocytes after spinal cord injury in mice alters wound healing and worsens neurological outcome. J Neurosci 2009, 29:753-764.

48. Ghasemlou N, Bouhy D, Yang J, Lopez-Vales R, Haber M, Thuraisingam T, He G, Radzioch D, Ding A, David S: Beneficial effects of secretory leukocyte protease inhibitor after spinal cord injury. Brain 2010, 133:126-138.

49. Schreiber J, Schachner M, Schumacher U, Lorke DE: Extracellular matrix alterations, accelerated leukocyte infiltration and enhanced axonal sprouting after spinal cord hemisection in tenascin-C-deficient mice. Acta Histochem 2013, 115:865-878.

50. Kuyumcu ME, Yesil Y, Ozturk ZA, Kizilarslanoglu C, Etgul S, Halil M, Ulger Z, Cankurtaran M, Ariogul S: The evaluation of neutrophil-lymphocyte ratio in Alzheimer's disease. Dement Geriatr Cogn Disord 2012, 34:69-74.

51. Gatto EM, Riobo NA, Carreras MC, Chernavsky A, Rubio A, Satz ML, Poderoso J): Overexpression of neutrophil neuronal nitric oxide synthase in Parkinson's disease. Nitric Oxide 2000, 4:534-539.

52. Davydova TV, Fomina VG, Voskresenskaya NI, Doronina OA: Phagocytic activity and state of bactericidal systems in polymorphonuclear leukocytes from patients with Alzheimer's disease. Bull Exp Biol Med 2003, 136:355-357.

53. Fortin CF, McDonald PP, Lesur O, Fulop T Jr: Aging and neutrophils: there is still much to do. Rejuvenation Res 2008, 11:873-882.

54. Jaremo P, Milovanovic M, Buller C, Nilsson S, Winblad B: Alzheimer's disease and granulocyte density diversity. Eur J Clin Invest 2013, 43:545-548.

55. Baik SH, Cha MY, Hyun YM, Cho H, Hamza B, Kim DK, Han SH, Choi H, Kim $\mathrm{KH}$, Moon M, Lee J, Kim M, Irimia D, Mook-Jung I: Migration of neutrophils targeting amyloid plaques in Alzheimer's disease mouse model. Neurobiol Aging 2014, 35:1286-1292.

56. Wojkowska DW, Szpakowski P, Ksiazek-Winiarek D, Leszczynski M, Glabinski A: Interactions between neutrophils, Th17 cells, and chemokines during the initiation of experimental model of multiple sclerosis. Mediat Inflamm 2014.

57. Carlson T, Kroenke M, Rao P, Lane TE, Segal B: The Th17-ELR+ CXC chemokine pathway is essential for the development of central nervous system autoimmune disease. J Exp Med 2008, 205:811-823.

58. Stoolman JS, Duncker PC, Huber AK, Segal BM: Site-specific chemokine expression regulates central nervous system inflammation and determines clinical phenotype in autoimmune encephalomyelitis. J Immunol 2014, 193:564-570.

59. Aube B, Levesque SA, Pare A, Chamma E, Kebir H, Gorina R, Lecuyer MA, Alvarez Jl, De Koninck Y, Engelhardt B, Prat A, Cote D, Lacroix S: Neutrophils Mediate Blood-Spinal Cord Barrier Disruption in Demyelinating Neuroinflammatory Diseases. J Immunol 2014, 193:2438-2454.

60. Easton AS: Neutrophils and stroke - can neutrophils mitigate disease in the central nervous system? Int Immunopharmacol 2013, 17:1218-1225.

61. Yin Y, Henzl MT, Lorber B, Nakazawa T, Thomas TT, Jiang F, Langer $R$, Benowitz LI: Oncomodulin is a macrophage-derived signal for axon regeneration in retinal ganglion cells. Nat Neurosci 2006 9:843-852.

62. Yin Y, Cui Q, Gilbert HY, Yang Y, Yang Z, Berlinicke C, Li Z, Zaverucha-doValle C, He H, Petkova V, Zack DJ, Benowitz LI: Oncomodulin links inflammation to optic nerve regeneration. Proc Natl Acad Sci U S A 2009, 106:19587-19592.

63. Kurimoto T, Yin Y, Habboub G, Gilbert HY, Li Y, Nakao S, Hafezi-Moghadam A, Benowitz LI: Neutrophils express oncomodulin and promote optic nerve regeneration. J Neurosci 2013, 33:14816-14824.

64. Nadeau S, Filali M, Zhang J, Kerr BJ, Rivest S, Soulet D, Iwakura Y, de Rivero Vaccari JP, Keane RW, Lacroix S: Functional recovery after peripheral nerve injury is dependent on the pro-inflammatory cytokines IL-1beta and TNF: implications for neuropathic pain. J Neurosci 2011, 31:12533-12542.

65. Liou JT, Lee CM, Lin YC, Chen CY, Liao CC, Lee HC, Day YJ: P-selectin is required for neutrophils and macrophage infiltration into injured site and contributes to generation of behavioral hypersensitivity following peripheral nerve injury in mice. Pain 2013, 154:2150-2159.

66. Barrette B, Hebert MA, Filali M, Lafortune K, Vallieres N, Gowing G, Julien JP, Lacroix S: Requirement of myeloid cells for axon regeneration.

J Neurosci 2008, 28:9363-9376.
67. Welte K: Granulocyte colony-stimulating factor (G-CSF): biochemistry, biology and pathophysiology. Klin Padiatr 1988, 200:157-164.

68. Levesque JP, Hendy J, Takamatsu Y, Williams B, Winkler IG, Simmons PJ: Mobilization by either cyclophosphamide or granulocyte colonystimulating factor transforms the bone marrow into a highly proteolytic environment. Exp Hematol 2002, 30:440-449.

69. Schneider A, Kuhn HG, Schabitz WR: A role for G-CSF (granulocyte-colony stimulating factor) in the central nervous system. Cell Cycle 2005, 4:1753-1757.

70. Schneider A, Kruger C, Steigleder T, Weber D, Pitzer C, Laage R, Aronowski J, Maurer MH, Gassler N, Mier W, Hasselblatt M, Kollmar R, Schwab S, Sommer C, Bach A, Kuhn HG, Schabitz WR: The hematopoietic factor G-CSF is a neuronal ligand that counteracts programmed cell death and drives neurogenesis. J Clin Invest 2005, 115:2083-2098.

71. Schabitz WR, Kollmar R, Schwaninger M, Juettler E, Bardutzky J, Scholzke MN, Sommer C, Schwab S: Neuroprotective effect of granulocyte colonystimulating factor after focal cerebral ischemia. Stroke 2003, 34:745-751.

72. Pitzer C, Kruger C, Plaas C, Kirsch F, Dittgen T, Muller R, Laage R, Kastner S, Suess S, Spoelgen R, Henriques A, Ehrenreich H, Schabitz WR, Bach A, Schneider A: Granulocyte-colony stimulating factor improves outcome in a mouse model of amyotrophic lateral sclerosis. Brain 2008, 131:3335-3347.

73. Yamasaki R, Tanaka M, Fukunaga M, Tateishi T, Kikuchi H, Motomura K, Matsushita T, Ohyagi $Y$, Kira J: Restoration of microglial function by granulocyte-colony stimulating factor in ALS model mice. J Neuroimmunol 2010, 229:51-62.

74. Diederich K, Sevimli S, Dorr H, Kosters E, Hoppen M, Lewejohann L, Klocke R, Minnerup J, Knecht S, Nikol S, Sachser N, Schneider A, Gorji A, Sommer C, Schabitz WR: The role of granulocyte-colony stimulating factor (G-CSF) in the healthy brain: a characterization of G-CSF-deficient mice. J Neurosci 2009, 29:11572-11581.

75. Morstyn G, Campbell L, Lieschke G, Layton JE, Maher D, O'Connor M, Green M, Sheridan W, Vincent M, Alton K: Treatment of chemotherapy-induced neutropenia by subcutaneously administered granulocyte colonystimulating factor with optimization of dose and duration of therapy. J Clin Oncol 1989, 7:1554-1562

76. Hoggatt J, Speth JM, Pelus LM: Concise review: Sowing the seeds of a fruitful harvest: hematopoietic stem cell mobilization. Stem Cells 2013, 31:2599-2606

77. Inada T, Takahashi H, Yamazaki M, Okawa A, Sakuma T, Kato K, Hashimoto M, Hayashi K, Furuya T, Fujiyoshi T, Kawabe J, Mannoji C, Miyashita T, Kadota R, Someya Y, Ikeda O, Hashimoto M, Suda K, Kajino T, Ueda H, Ito Y, Ueta T, Hanaoka H, Takahashi K, Koda M: Multicenter prospective nonrandomized controlled clinical trial to prove neurotherapeutic effects of granulocyte colony-stimulating factor for acute spinal cord injury: analyses of follow-up cases after at least 1 year. Spine (Phila Pa 1976) 2014, 39:213-219.

78. Takahashi H, Kato M, Kikuchi A, Hanada R, Koh K: Delayed short-term administration of granulocyte colony-stimulating factor is a good mobilization strategy for harvesting autologous peripheral blood stem cells in pediatric patients with solid tumors. Pediatr Transplant 2013, 17:688-693.

79. Takahashi H, Yamazaki M, Okawa A, Sakuma T, Kato K, Hashimoto M, Hayashi K, Furuya T, Fujiyoshi T, Kawabe J, Yamauchi T, Mannoji C, Miyashita T, Kadota R, Hashimoto M, Ito Y, Takahashi K, Koda M: Neuroprotective therapy using granulocyte colony-stimulating factor for acute spinal cord injury: a phase I/lla clinical trial. Eur Spine J 2012, 21:2580-2587.

80. Lee JS, Yang CC, Kuo YM, Sze Cl, Hsu JY, Huang YH, Tzeng SF, Tsai CL, Chen $\mathrm{HH}$, Jou IM: Delayed granulocyte colony-stimulating factor treatment promotes functional recovery in rats with severe contusive spinal cord injury. Spine (Phila Pa 1976) 2012, 37:10-17.

81. Dittgen T, Pitzer C, Plaas C, Kirsch F, Vogt G, Laage R, Schneider A: Granulocyte-colony stimulating factor (G-CSF) improves motor recovery in the rat impactor model for spinal cord injury. PLoS One 2012, 7:e29880.

82. Nishio Y, Koda M, Kamada T, Someya Y, Kadota R, Mannoji C, Miyashita T, Okada S, Okawa A, Moriya H, Yamazaki M: Granulocyte colony-stimulating factor attenuates neuronal death and promotes functional recovery after spinal cord injury in mice. J Neuropathol Exp Neurol 2007, 66:724-731.

83. Guo Y, Liu S, Wang P, Zhang H, Wang F, Bing L, Gao J, Yang J, Hao A: Granulocyte colony-stimulating factor improves neuron survival in experimental spinal cord injury by regulating nucleophosmin-1 expression. J Neurosci Res 2014, 92:751-760. 
84. Sanli AM, Serbes G, Caliskan M, Kaptanoglu E, Sargon MF, Kilinc K, Besalti O, Sekerci Z: Effect of granulocyte-colony stimulating factor on spinal cord tissue after experimental contusion injury. J Clin Neurosci 2010, 17:1548-1552.

85. Chen CH, Huang SY, Chen NF, Feng CW, Hung HC, Sung CS, Jean YH, Wen $\mathrm{ZH}$, Chen WF: Intrathecal granulocyte colony-stimulating factor modulate glial cell line-derived neurotrophic factor and vascular endothelial growth factor A expression in glial cells after experimental spinal cord ischemia. Neuroscience 2013, 242:39-52.

86. Guo X, Bu X, Li Z, Yan Z, Jiang J, Zhou Z: Comparison of autologous bone marrow mononuclear cells transplantation and mobilization by granulocyte colony-stimulating factor in experimental spinal injury. Int J Neurosci 2012, 122:723-733.

87. Guo Y, Zhang H, Yang J, Liu S, Bing L, Gao J, Hao A: Granulocyte colonystimulating factor improves alternative activation of microglia under microenvironment of spinal cord injury. Neuroscience 2013, 238:1-10.

88. Osada T, Watanabe M, Hasuo A, Imai M, Suyama K, Sakai D, Kawada H, Matsumae M, Mochida J: Efficacy of the coadministration of granulocyte colony-stimulating factor and stem cell factor in the activation of intrinsic cells after spinal cord injury in mice. J Neurosurg Spine 2010 13:516-523.

89. Kadota R, Koda M, Kawabe J, Hashimoto M, Nishio Y, Mannoji C, Miyashita T, Furuya T, Okawa A, Takahashi K, Yamazaki M: Granulocyte colonystimulating factor (G-CSF) protects oligodendrocyte and promotes hindlimb functional recovery after spinal cord injury in rats. PLoS One 2012, 7:e50391.

90. Wipke BT, Allen PM: Essential role of neutrophils in the initiation and progression of a murine model of rheumatoid arthritis. J Immunol 2001, 167:1601-1608.

91. Tsuboi N, Asano K, Lauterbach M, Mayadas TN: Human neutrophil Fcgamma receptors initiate and play specialized nonredundant roles in antibody-mediated inflammatory diseases. Immunity 2008, 28:833-846.

92. Fujishima S, Morisaki H, Ishizaka A, Kotake Y, Miyaki M, Yoh K, Sekine K, Sasaki J, Tasaka S, Hasegawa N, Kawai Y, Takeda J, Aikawa N: Neutrophil elastase and systemic inflammatory response syndrome in the initiation and development of acute lung injury among critically ill patients. Biomed Pharmacother 2008, 62:333-338.

93. Soehnlein O, Zernecke A, Eriksson EE, Rothfuchs AG, Pham CT, Herwald H, Bidzhekov K, Rottenberg ME, Weber C, Lindbom L: Neutrophil secretion products pave the way for inflammatory monocytes. Blood 2008, 112:1461-1471.

94. Silva MT: When two is better than one: macrophages and neutrophils work in concert in innate immunity as complementary and cooperative partners of a myeloid phagocyte system. J Leukoc Biol 2010, 87:93-106.

95. Butterfield TA, Best TM, Merrick MA: The dual roles of neutrophils and macrophages in inflammation: a critical balance between tissue damage and repair. J Athl Train 2006, 41:457-465.

96. Mantovani A, Cassatella MA, Costantini C, Jaillon S: Neutrophils in the activation and regulation of innate and adaptive immunity. Nat Rev Immunol 2011, 11:519-531.

97. Tong X, Lv G, Huang J, Min Y, Yang L, Charles Lin P: Gr-1+CD11b+ myeloid cells efficiently home to site of injury after intravenous administration and enhance diabetic wound healing by neoangiogenesis. J Cell Mol Med 2014, 18:1194-1202.

98. Schruefer R, Lutze N, Schymeinsky J, Walzog B: Human neutrophils promote angiogenesis by a paracrine feedforward mechanism involving endothelial interleukin-8. Am J Physiol Heart Circ Physiol 2005, 288:H1186-H1192.

99. Fridlender ZG, Sun J, Kim S, Kapoor V, Cheng G, Ling L, Worthen GS, Albelda SM: Polarization of tumor-associated neutrophil phenotype by TGF-beta: "N1" versus "N2" TAN. Cancer Cell 2009, 16:183-194.

doi:10.1186/s12974-014-0150-2

Cite this article as: Neirinckx et al:: Neutrophil contribution to spinal cord injury and repair. Journal of Neuroinflammation 2014 11:150.

\section{Submit your next manuscript to BioMed Central and take full advantage of:}

- Convenient online submission

- Thorough peer review

- No space constraints or color figure charges

- Immediate publication on acceptance

- Inclusion in PubMed, CAS, Scopus and Google Scholar

- Research which is freely available for redistribution

Submit your manuscript at www.biomedcentral.com/submit
C Biomed Central 